\title{
Plant pigments content as a marker for herbicide abiotic stress in corn (Zea mays L.)
}

\author{
Svetla Yancheva1, Lidiya Georgieva ${ }^{1 *}$, Milena Kostova1, Pervin Halkoglu1, Maya Dimitrova ${ }^{2}$, Samir Naimov ${ }^{3}$ \\ ${ }^{1}$ Department of Genetics and Plant Breeding, Faculty of Agronomy, Agricultural University- Plovdiv, 4000 Plovdiv, Bulgaria, ${ }^{2}$ Department of \\ Farming and Herbology, Faculty of Agronomy, Agricultural University-Plovdiv, 4000 Plovdiv, Bulgaria, ${ }^{3}$ Department of Plant Physiology and \\ Molecular Biology, University of Plovdiv "P. Hilendarski", 4000 Plovdiv, Bulgaria
}

\section{A B S T R A C T}

\begin{abstract}
The effect of the soil herbicide isoxaflutole on the growth and development of new corn hybrids in controlled conditions was studied. Conducted assays confirmed that tested hybrids exhibit different sensitivity to herbicide treatment, expressed as a decrease of chlorophyll or increase of anthocyanin content. The lowest content of chlorophylls was determined for hybrid P0216 and the highest anthocyanin levels were observed for hybrid P9241. Present investigation was performed for evaluation the toxic effect of the herbicide and demonstrated that plant pigment content can be used as a marker for abiotic stress. This study could be very useful for practical applications as a preliminary test for phytotoxicity and/or sensitivity of different crops or model plants to herbicides.
\end{abstract}

Keywords: Anthocyanins; Chlorophylls; Herbicide; Stress; Zea mays L.

\section{INTRODUCTION}

Maize (Zea mays L.) is grown as a fodder crop for forage and occupied second place in the cultivation after wheat in Bulgaria. It is highly sensitive to weed infestation in the early stages of its development, especially in cases with delayed seed germination because of unfavorable conditions. Agricultural practice has shown that the grain yield could decline between 70 and $90 \%$ in highly weeding maize fields (Troyer, 2009; Mahanna et al., 2014).

Weeds can be controlled through the timely removal or by treatment with herbicides, which in turn can provoke chemical changes in the development of crop plant (Kabambe et al., 2008). Application of chemical agents on the base of isoxaflutole have been used for weed control in economically important crops such corn (Nelson and Penner, 2006; Wicks et al., 2007; de Goes Maciel et al., 2012; Robinson et al., 2013) and sugarcane (Azania et al., 2010) with described phytotoxicity. The treatment with chemical agents considerably hamper the process of photosynthesis in most plants by altering the ultrastructure of the organelles and concentration of various pigments and metabolites including enzymes involved in this process (Ashraf and Harris, 2013). It is known that the actions of some herbicides as inhibition or blocking the synthesis of chlorophyll (Fai et al., 2007) and/or anthocyanins biosynthesis are a typical response of plants exposed to stress (Misyura et al., 2012).

Moreover, the toxic effect of isoxaflutole residues was established in vegetable crops as adzuki bean, alfalfa, carrot, cucumber, dry bean (navy and black beans), onion, sugar beet, tomato (Nelson and Penner 2005), cabbage and sugarbeets (Soltani et al., 2005), tomato, bell pepper, cabbage, snapbean and cucumber (Felix and Doohan, 2005). The active substance distributed through the vascular tissue acts as an inhibitor of plant pigment biosynthesis (Pallett et al., 1998).

The aim of the present work was to investigate the effect of herbicide Merlin Flex 480 SC (active substance isoxaflutole + cyprosulfamide antidote) on the growth of new corn hybrids in controlled conditions by examination of the pigment content (chlorophylls and anthocyanins) as indicator for crop sensitivity.

\footnotetext{
${ }^{*}$ Corresponding author:

Lidiya Dimitrova Georgieva, Department of Genetics and Plant Breeding, Faculty of Agronomy, Agricultural University- Plovdiv, 4000 Plovdiv, Bulgaria. E-mail: lid_georgieva@abv.bg
} 


\section{MATERIALS AND METHODS}

\section{Plant material}

Seeds of five new forage maize hybrids (P0023, P0216, P9241, P9900 and P9915 of company Pioneer Seeds Bulgaria), kindly provided by Prof. T. Tonev from the Department of Farming and Herbology, Agricultural University-Plovdiv, Bulgaria were germinated in $14 \mathrm{~cm}$ (diameter) petri dishes in with wet filter paper. The treatment with isoxaflutole [5-cyclopropyl-4-(2-methane sulfonyl-4-trifluoromethylbenzoyl) isoxazole], active substance of commercial form Merlin Flex 480 SC was performed at the recommended for field treatment dose $(420 \mathrm{ml} / \mathrm{ha})$. For the purpose of the experiment this dose was recalculated according to the dish area by the formula: $\mathrm{S}=\pi \cdot \mathrm{r}^{2}$ and needed dilution. Herbicide solution $(5 \mathrm{ml})$ was applied only on the bottom filter paper of the petri dishes. Control variants were prepared by soaking of the filter paper only with distillated water. The experiment was conducted under controlled conditions at $25^{\circ} \mathrm{C}$ and 16/8 h photoperiod (2500 Lux). Data analysis based on two replications with 25 seeds per each variant.

Seven days old sprouts and roots showing symptoms of toxicity (albino and purple forms) and normally developing green shoots were subjected to biochemical assay. A control from untreated seeds was prepared as a bulk sample.

Additionally the 14-days old sprouts (albino and purple forms) followed treatment with herbicide were transplanted to peat: perlite (1:1) mixture for investigation of their subsequent development. Cultivation was performed in a growth chamber at $23^{\circ} \mathrm{C}$ and $16 / 8 \mathrm{~h}$ photoperiod (2500 Lux).

\section{Chlorophyll extraction}

Samples (100-150 mg) were ground thoroughly with 85\% acetone (solid/solvent ratio 1:40). The extraction was followed by centrifugation for 5 minutes at $6000 \mathrm{rpm}$. The analytical determination of chlorophyll $a$, chlorophyll $b$ and chlorophyll $a+b$ was performed spectrophotometrically at tree wavelengths of 663, 664 and $644 \mathrm{~nm}$ according to the method described by Lichtenthaler and Wellburn (1983).

\section{Anthocyanin extraction}

Samples (100-150 mg) were ground thoroughly with 1\% $\mathrm{HCl}$ dissolved in methanol (solid/solvent ratio 1:10) and following centrifugation for 5 minutes at $6000 \mathrm{rpm}$. For the determination of total content of anthocyanins two buffers were used: buffer 1) $\mathrm{KCl} \mathrm{pH=1.0} \mathrm{and} \mathrm{buffer} \mathrm{2)}$ $\mathrm{CH} 3 \mathrm{COONa} \mathrm{pH}=4.5$. The absorbance of each sample was measured by a spectrophotometer at two wavelengths 520 and $700 \mathrm{~nm}$. Determination of anthocyanin content was performed as described by Lee et al. (2005).

\section{RESULTS AND DISCUSSION}

The seeds of the tested hybrids P0023, P0216, P9241, P9900 and P9915, treated with herbicide showed 100\% germination but development of green, purple and albino sprouts was observed. Tolerant hybrids posses ability to rapidly metabolize this type of herbicide compared to sensitive hybrids.

The results for analyzed content of chlorophyll $a, b$ and $a+b$, calculated as $\mathrm{mg} / \mathrm{g}$ fresh weight $(\mathrm{FW})$ is presented in Fig. 1. The lowest values of chlorophyll $a$ were established for white sprouts, ranging between $0.019 \pm 0.003 \mathrm{mg} / \mathrm{g}$ FW for hybrid P9241 to $0.061 \pm 0.001 \mathrm{mg} / \mathrm{g}$ FW for hybrid P0023. In the purple shoots established amounts were between $0.030 \pm 0.001 \mathrm{mg} / \mathrm{g} \mathrm{FW}$ (P0216) and $0.187 \pm 0.021 \mathrm{mg} / \mathrm{g}$ FW (P0023) (Fig. 1A). In the treated seeds developing green shoots, phytotoxic effect was not observed. The highest chlorophyll $a$ amounts were found for hybrids

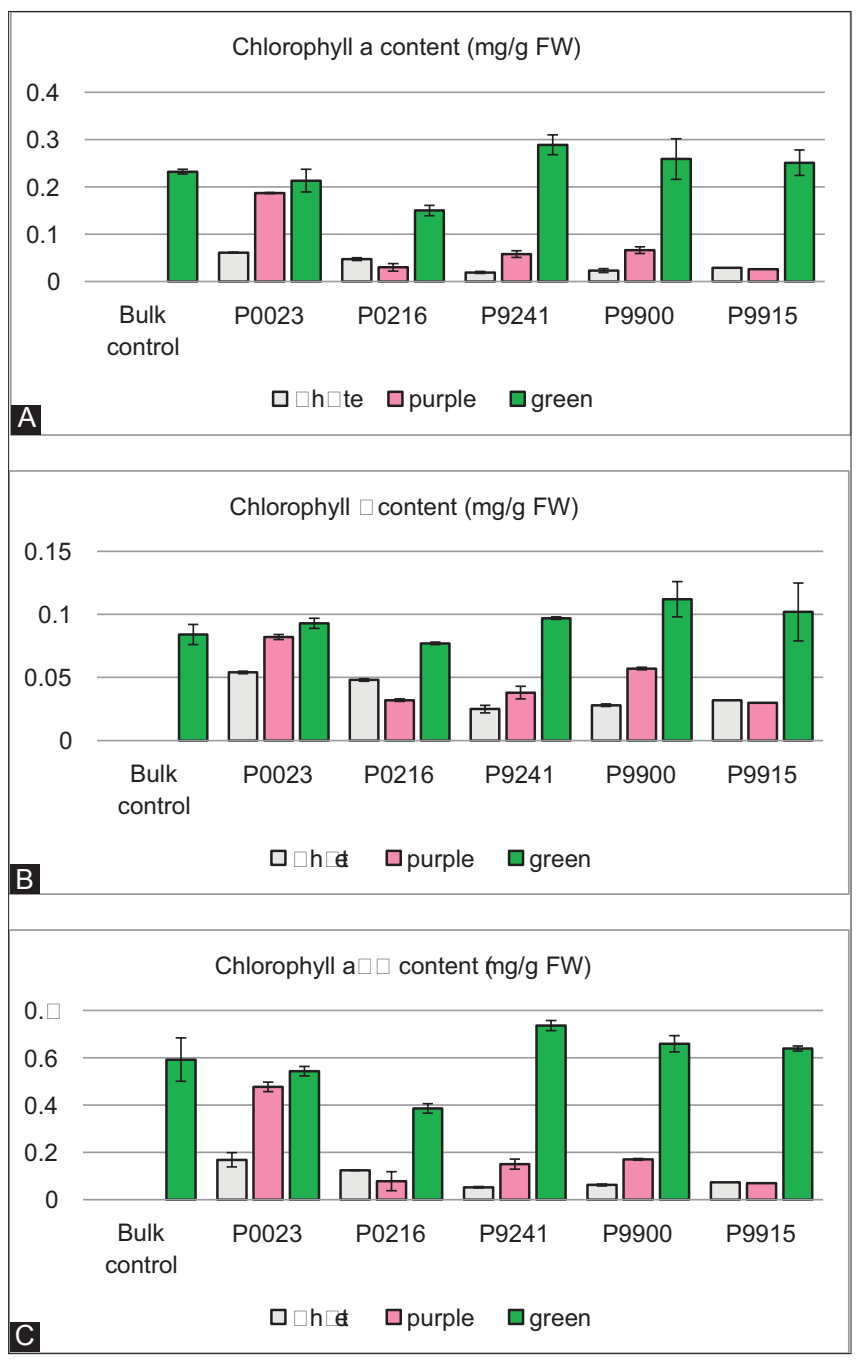

Fig 1. Chlorophyll content in white, purple and green sprouts as $\mathrm{mg} / \mathrm{g}$ $\mathrm{FW}$ (bars $\pm \mathrm{SD}$ ). 
P9241 (0.289 $\pm 0.021 \mathrm{mg} / \mathrm{g} \mathrm{FW})$, P9900 (0.259 $\pm 0.043 \mathrm{mg} / \mathrm{g}$ $\mathrm{FW})$ and P9915 (0.251 $\pm 0.027 \mathrm{mg} / \mathrm{g} \mathrm{FW})$, while in the control group the content of chlorophyll $a$ was $0.232 \pm 0.050 \mathrm{mg} / \mathrm{g}$ FW. For the hybrids P0216 and P0023, forming green shoots the lowest content of chlorophyll $a$ (respectively $0.150 \pm 0.011 \mathrm{mg} / \mathrm{g} \mathrm{FW}$ and $0.213 \pm 0.024 \mathrm{mg} / \mathrm{g}$ FW) was determined (Fig. 1A).

Data analysis for chlorophyll $b$ showed lower amount than those established for chlorophyll $a$ (Fig. 1B). The content of chorophyll $b$ in the purple shoots showed higher values comparing to the white forms. This can be explained by the fact that under the action of stress factors the plants retain the biosynthesis of chlorophyll and direct the metabolism to synthesis of anthocyanins (Kannangara and Hansson, 1998). In the green shoots without visible phytotoxic effect, chlorophyll $b$ content was the highest and varied between $0.093 \pm 0.004 \mathrm{mg} / \mathrm{g} \mathrm{FW}$ for P0023 and $0.112 \pm 0.014 \mathrm{mg} / \mathrm{g}$ FW for P9900.

Only in hybrid P0216 was established a lower value $(0.077 \pm 0.001 \mathrm{mg} / \mathrm{g} \mathrm{FW})$ of chlorophyll $b$ compared to the control $(0.084 \pm 0.008 \mathrm{mg} / \mathrm{g}$ FW) (Fig. 1B).

The total content of chlorophyll $a+b$ in green sprouts confirmed the established for chlorophyll $a$ trend. The highest values of the pigments were recorded in a hybrid P9241 (Fig. 1C). It is interesting that in hybrid P0023 was established the highest content of chlorophyll $a, b$ and $a+b$ in the analyzed purple shoots and albino forms (Fig. 1).

An additional experiment for evaluation of the content of chlorophyll $a, b$ and $a+b$ was probed using roots of the treated by herbicide seeds (Fig. 2).

The established amount of chlorophyll $a$ in the roots from untreated bulk control was $0.020 \pm 0.001 \mathrm{mg} / \mathrm{g}$ FW. For the herbicide treated samples the concentrations of chlorophyll $a$ were between $0.015 \pm 0.001 \mathrm{mg} / \mathrm{g}$ FW (P9241) and $0.032 \pm 0.003 \mathrm{mg} / \mathrm{g} \mathrm{FW}$ (P9900). The highest values were observed for P9915 $(0.026 \pm 0.004 \mathrm{mg} / \mathrm{g} \mathrm{FW})$ and P9900 (0.032 $\pm 0.003 \mathrm{mg} / \mathrm{g} \mathrm{FW})$ and the lowest results were established for hybrids P9241 $(0.015 \pm 0.001 \mathrm{mg} / \mathrm{g}$ FW), P0023 (0.018 $0.001 \mathrm{mg} / \mathrm{g} F W)$ and P0216 (0.020 $\pm 0.004 \mathrm{mg} / \mathrm{g} \mathrm{FW})$.

Calculated amount of chlorophyll $b$ in the control was $0.029 \pm 0.001 \mathrm{mg} / \mathrm{g}$ FW. The results obtained for the treated hybrids varied between $0.026 \pm 0.001$ and $0.038 \pm 0.001 \mathrm{mg} / \mathrm{g}$ FW.

Data analysis for total content of chlorophyll $a+b$ followed the established for chlorophyll $a$ dependence. It is important to note that amounts of chlorophyll $a+b$ in the

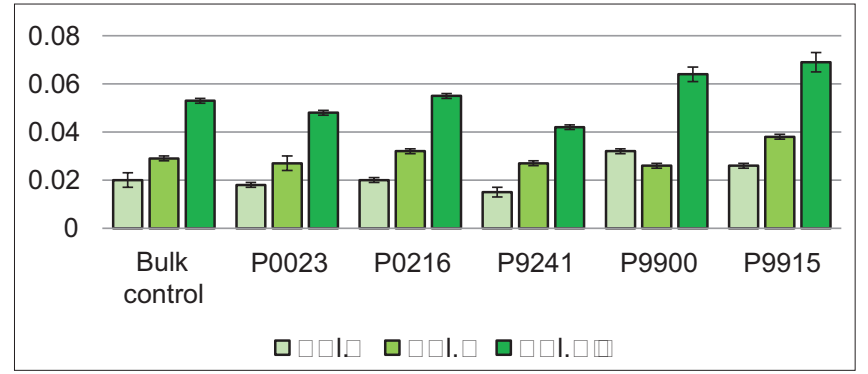

Fig 2. Chlorophyll content in the roots as $\mathrm{mg} / \mathrm{g} \mathrm{FW}$ (bars $\pm \mathrm{SD}$ ).

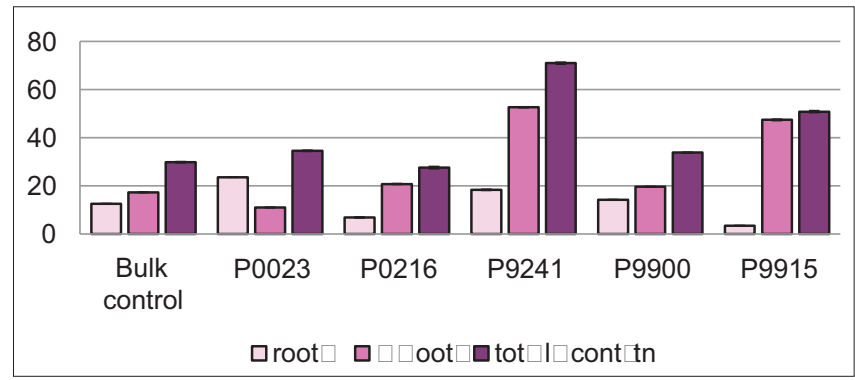

Fig 3. Anthocyanin content in roots and shoots as mg/g FW (bars $\pm S D$ ).

tested genotypes were comparable with the established ones for the control. The synthesis of chlorophyll in the roots is untypical and in the case could be explained by the exposure to light (16/8 $\mathrm{h}$ photoperiod). Similar observations and results have been also reported by Björn and Odhelius (1966) describing the synthesis of chlorophylls in the roots of cucumber and peas having access to light.

We observed that the treatment with herbicide causes inhibition of the growth of the studied hybrids. This effect was associated with the development of purple forms and confirmed by examination of the anthocyanin content from extracts of purple roots and shoots.

Results presented in Fig. 3 show that the highest anthocyanin content was recorded for hybrid P9241 (70.99 $\pm 0.41 \mu \mathrm{g} / \mathrm{g}$ $\mathrm{FW}$ ) and only in hybrid P0216 the total anthocyanin content was lower $(27.52 \pm 0.45 \mu \mathrm{g} / \mathrm{g}$ FW) compared to the control $(29.79 \pm 0.20 \mu \mathrm{g} / \mathrm{g} \mathrm{FW})$.

The phytotoxic effect of the herbicide on corn sprouts had an adaptive character. Transplantation of 14-days old sprouts followed the herbicide treatment (albino and purple forms) to peat: perlite (1:1) mixture resulted in subsequent development of corn plants overcoming the stress induced by the herbicide Merlin Flex ${ }^{\circledR} 480$ SC. Within next weeks they continued to grow as normal green plants (Fig. 4).

It is known that the action of some herbicides as inhibition or blocking the synthesis of chlorophyll (Fai et al., 2007) and/or increased anthocyanin biosynthesis are a typical response of plants to stress (Misyura et al., 


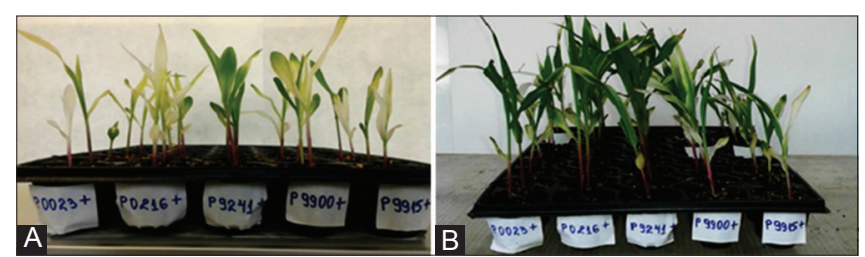

Fig 4. Development of corn plantlets of the tested hybrids after transplantation to peat: perlite mixture: A - day $14, \mathrm{~B}$ - day 21 .

2012). Moreover, some abiotic factors affect the level of anthocyanin and chlorophyll synthesis in many plant species, serving as an indication of stress. For example, Fai et al. (2007) successfully used the measurement of the chlorophyll a levels, as a marker for the toxicity of green algae. Doong et al. (1993) studied the changes in chlorophyll and anthocyanin levels and accounted the phytochemical stress induced in the treatment of Hydrilla with fluridone.

Isoxaflutole is a pre-emergence herbicide for the control of a wide range of broadleaf and grassy weeds in corn and sugarcane (Luscombe et al., 1995). It is an inhibitor of 4-hydroxyphenylpyruvatedioxygenase (4-HPPD) and causes leaf bleaching in susceptible species (Pallett et al.,1998, 2001).

Based on the data analysis hybrid P0216 could be defined as the most sensitive and in contrast, P9241 as a tolerant genotype. Presented results confirm previous observations of Hager and McGlamery (1999) from field tests that corn generally has good tolerance to isoxaflotole (Balance) because the corn plant can rapidly metabolize the active ingredient to non-phytotoxic forms.

\section{CONCLUSION}

The conducted investigation for determination of the total chlorophyll and anthocyanin contents, provide reliable results for sensitivity of some new corn hybrids to herbicide isoxaflotole (Merlin Flex ${ }^{\circledR} 480$ SC). The biochemical analysis of plant pigments and later plant development confirmed the adaptive character of the phytotoxic effect of the applied herbicide. This study may be very useful for practical applications as a preliminary test. It is a basis to recommend such type of analyses for evaluation of different toxic compounds, especially for the new herbicide products on the market and the ability to obtain initial information for phytotoxicity and/or sensitivity of different crops or model plants to herbicides.

\section{Author contribution}

All authors contributed equally in this article.

\section{REFERENCES}

Ashraf, M. and P. J. C. Harris. 2013. Photosyntesis under stressful environments: An overview. Photosyntetica. 51(2): 163-190.

Azania, C. A. M., A. R. Schiavetto, F. S. Zera, C. M. Lorenzato, A. A. M. Azania and A. Borges. 2010. Evaluation of herbicides applied on sugar cane during rainy season in Brazil. Rev. Chil. Hist. Nat. 9(1): 9-16.

Björn, L. O. and I. Odhelius. 1996. Chlorophyll formation in excised roots of cucumber and pea. Physiol. Plant. 19: 60-62.

de Goes Maciel, D. C., E. D. Velini, D. Martins, E. Negrisoli and G. R. Tofolli. 2012. Corn seed treatment with naphthalic anhydride against isoxaflutole phytotoxication action. J. Food Agric. Environ. 10(1): 612-616.

Doong, R. L., G. E. Macdonald and D. G. Shilling. 1993. Effect of fluridone on chlorophyll, carotenoids and anthocyanin content of Hydrilla. J. Aquat. Plant Manag. 31: 55-59.

Fai, P. B., A. Grant, B. Reid. 2007. Chlorophyll a fluorescence as a biomarker for rapid toxicity assessment. Environ. Toxicol. Chem. 26(7): 1520-1531.

Felix, J. and D. J. Doohan. 2005. Response of five vegetable crops to isoxaflutole soil residues. Weed Technol. 19(2): 391-396.

Kabambe, V. H., F. Kanampiu and A. Ngwira. 2008. Imazapyr (herbicide) seed dressing increases yield, suppresses Striga asiatica and has seed depletion role in maize (Zea mays L.) in Malawi. Afr. J. Biotechnol. 7(18): 3293-3298.

Kannangara, G. C. and M. Hansson. 1998. Arrest of chlorophyll accumulation prior to anthocyanin formation in Euphorbia pulcherrima. Plant Physiol. Biochem. 36(12): 843-848.

Lee, J., R. W. Durst and R. E. Wrolstad. 2005. Determination of total monomeric anthocyanin pigment content of fruit juices, beverages, natural colorants, and wines by the $\mathrm{pH}$ differential method: Collaborative study. J. AOAC. Int. 88: 1269-1278.

Lichtenthaler, H. K. and A. R. Wellburn. 1983. Determinations of total carotenoids and chlorophylls $a$ and $b$ of leaf extracts in different solvents. Biochem. Soc. Trans. 11: 591-592.

Luscombe, B. M., K. E. Pallett, P. Loubiere, J. C. Millet, J. Melgarejo and T. E. Vrabel. 1995. RPA 201772, a novel herbicide for broad leaf and grass weed control in maize and sugar cane. BCPC. Weeds. 1: 35-42.

Mahanna, B., B. Seglar, F. Owens, S. Dennis and R. Newell. 2014. In: Johnston, I. A. (Ed.), Silage Zone Manual. Du Pont Pioneer. Johnston, IA.

Misyura, M., J. Colasanti and S. J. Rothstein. 2012. Physiological and genetic analysis of Arabidopsis thaliana anthocyanin biosynthesis mutants under chronic adverse environmental conditions. J. Exp. Bot. 1-12.

Nelson, E. A. and D. Penner. 2005. Sensitivity of selected crops to isoxaflutole in soil and irrigation water. Weed Technol. 19(3): 659-663.

Nelson, E. A. and D. Penner. 2006. Reduction of isoxaflutole injury to corn (Zea mays) with herbicide safeners and water-repellent adjuvants. Weed Technol. 20(4): 999-1003.

Pallett, K. E., J. P. Little, M. Sheekey and P. Veerasekaran. 1998. The mode of action of isoxaflutole: I. Physiological effects, metabolism, and selectivity. Pestic. Biochem. Physiol. 62(2): 113-124.

Pallett, K. E., S. M. Cramp, J. P. Little, P. Veerasekaran, A. J. Crudace and A. E. Slater. 2001. Isoxaflutole: The background to its discovery and the basis of its herbicidal properties. Pest Manag. Sci. 57: 133-142. 
Robinson, E. D., N. Soltanil, C. Shropshire and P. H. Sikkema. 2013. Cyprosulfamide safens isoxaflutole in sweet corn (Zea mays L.). Hortscience. 48(10): 1262-1265.

Soltani, N., P. H. Sikkema and D. E. Robinson. 2005. Effect of foramsulfuron and isoxaflutole residues on rotational vegetable crops. Hortscience. 40(3): 620-622.

Troyer, A. F. 2009. Development of hybrid corn and the seed corn industry. In: Bennetzen J. L. and S. Hake, (Eds.), Maize Handbook: Genetics and Genomics, Vol. II. Springer, New York, Pp. 87-95.

Wicks, A. G., S. Z. Knezevic, M. Bernards, R. G. Wilson, R. N. Klein and A. R. Martin. 2007. Effect of planting depth and isoxaflutole rate on corn injury in Nebraska. Weed Technol. 21(3): 642-646. 